\title{
High-normal blood pressure is associated with microalbuminuria in the general population: the Watari study
}

\begin{abstract}
Masanori Munakata ${ }^{1,2}$, Satoshi Konno ${ }^{1,2}$, Mizuho Ohshima ${ }^{2}$, Tamon Ikeda ${ }^{3}$, Yukio Miura ${ }^{1}$ and Sadayoshi Ito ${ }^{4}$
Microalbuminuria, for which hypertension and diabetes are well-known risk factors, has recently been used to detect individuals at risk for cardiovascular and chronic kidney diseases in the general population. We aimed to determine the thresholds of blood pressure or blood glucose concentration at which the odds ratio of having microalbuminuria begins to increase. An annual public health checkup was conducted on 3166 participants aged 29-84 years (mean, $61 \pm 11$ years; $40 \%$ men) living in Watari town, Japan. We studied their demographic data, medical history of hypertension, diabetes, dyslipidemia, sitting blood pressure and fasting blood samples. Urinary albumin excretion was examined in terms of the albumin/creatinine ratio in spot urine samples. Microalbuminuria was defined as 30-299 mg albumin per gram creatinine. Final analyses included 2133 participants under no anti-hypertensive or anti-diabetic medication. Microalbuminuria was detected in 118 subjects (5.5\%). We used the adjusted odds ratios for microalbuminuria in different blood pressure and blood glucose groupings as the reference. The adjusted odds ratio increased linearly with increase in systolic blood pressure. A similar trend, although not as linear, was observed with diastolic blood pressure. The odds ratio increased significantly with high-normal levels of both systolic and diastolic blood pressure. For blood glucose, the adjusted odds ratio increased significantly from the impaired fasting glucose level. Therefore, the odds ratio for microalbuminuria begins to increase from high-normal blood pressure and impaired fasting glucose levels in comparison with the reference. Early intervention in such cases may be useful for reducing cardiovascular and renal risks.
\end{abstract} Hypertension Research (2011) 34, 1135-1140; doi:10.1038/hr.2011.98; published online 28 July 2011

Keywords: blood pressure; general population; glucose metabolism; microalbuminuria

\section{INTRODUCTION}

A new health checkup system was introduced in Japan in 2008. This system aims to prevent lifestyle-related diseases such as diabetes through the early detection and intervention of metabolic syndrome. ${ }^{1}$ Although this preventive strategy should be beneficial, long-term observation with hard endpoints is necessary to demonstrate its effects. Meanwhile, the combined use of surrogate endpoints could make it possible to identify high-risk patients and to assess the effectiveness of lifestyle guidance in the short term.

Microalbuminuria is considered a marker of glomerular as well as systemic vascular endothelial injuries. ${ }^{2,3}$ It has been shown that microalbuminuria is associated with higher risks of cardiovascular and end-stage renal disease in not only patients of several diseases ${ }^{4-7}$ but also in the general population. ${ }^{8,9}$

The apparent modifiable risks of microalbuminuria are diabetes and hypertension. However, there are extremely few reports from large-scale studies that examine blood pressure and blood glucose levels at which the risk of microalbuminuria begins to increase. ${ }^{10-13}$ Moreover, no such study has been conducted in Asia. If the purpose of the new health checkup system is to prevent cardiovascular or renal disease, interventions should preferably be made as soon as possible and at an early and appropriate stage. Therefore, this cross-sectional study aims to identify the thresholds of blood pressure and blood glucose at which the odds ratio of the presence of microalbuminuria begins to rise.

\section{METHODS}

This study was conducted in Watari town, which is located $\sim 26 \mathrm{~km}$ south of Sendai city where Tohoku Rosai Hospital and Tohoku University are located. In 2008, the registered population in Watari town was 35132 , and all inhabitants were Japanese. The eastern side of the town faces the Pacific Ocean. Because of the warm climate, the fruit tree cultivation and fishing industries flourish; their related manufacturing, retail and sales are the main industries.

As a general rule, the health checkup participants were residents who received healthcare benefits from the town. The participants comprised both men and women who worked in or whose family members were engaged in typically self-employed occupations, such as agriculture, fisheries, forestry and retail trade, including retirees. The number of candidates in 2008 was 6675 .

\footnotetext{
1Preventive Medical Center, Tohoku Rosai Hospital, Sendai, Japan; ${ }^{2}$ Division of Hypertension, Tohoku Rosai Hospital, Sendai, Japan; ${ }^{3}$ Division of Internal Medicine, Akita Rosai Hospital, Oodate, Japan and ${ }^{4}$ Division of Nephrology, Endocrinology and Vascular Medicine, Tohoku University Graduate School of Medicine, Sendai, Japan Correspondence: Dr M Munakata, Preventive Medical Center, Tohoku Rosai Hospital, 3-21 Dainohara 4, Aobaku, Sendai 981-8563, Japan. E-mail: munakata.@tohokuh.rofuku.go.jp
}

Received 18 November 2010; revised 15 April 2011; accepted 18 April 2011; published online 28 July 2011 
The survey items in the questionnaire concerned medical history, drug treatment history, smoking habits, diet and exercise habits. The anthropometric measurements consisted of height, weight, body mass index and abdominal circumference. Blood pressure was measured in a sitting position after 5-min of rest by using an automated sphygmomanometer (BX-10; Omron Colin, Kyoto, Japan).

Morning blood after at least 10-h fasting was collected to examine liver function (that is, aspartate aminotransferase, alanine transaminase and gammaglutamyl transpeptidase), lipids (that is, triglycerides, high-density lipoprotein and low-density lipoprotein), glucose metabolism (that is, fasting blood sugar and hemoglobin Alc), and serum uric acid and creatinine concentrations. Hemoglobin Alc level was measured using HPLC (HLC723G7; Tohso, Yamaguchi, Japan). Fasting blood sugar levels were determined using a Hitachi 7700P apparatus (Hitachi, Tokyo, Japan). The remaining biochemical markers were determined using a standard automatic analyzer (7700DD; Hitachi). The estimated glomerular filtration ratio was calculated on the basis of the following formula provided by the Japanese Society of Nephrology: glomerular filtration ratio $=194 \times \mathrm{Cr}^{-1.094} \times \mathrm{age}^{-0.287} \mathrm{ml} \mathrm{min}^{-1}$ per $\left.1.73 \mathrm{~m}^{2}\right) \times 0.739$ (women). ${ }^{14} \mathrm{We}$ diagnosed metabolic syndrome based on the Japanese criteria. ${ }^{15}$

In addition to the general urine dipstick test, urinary albumin concentration was measured by the turbidimetric method (Au600; Olympus, Tokyo, Japan) using the morning spot urine sample. Urinary creatinine concentration was simultaneously measured by the enzymatic method. The urinary albumin excretion rate was calculated after adjusting the creatinine concentration.

To determine the occurrence of microalbuminuria, we first used the traditional cutoff values of $\geqslant 30$ and $<300 \mathrm{mgg}^{-1} \mathrm{Cr}^{16}$ However, the lower cutoff value remains debatable, because a urinary albumin excretion of $<30 \mathrm{mgg}^{-1} \mathrm{Cr}$ is also linearly associated with a risk of cardiovascular events. ${ }^{9,17}$ Therefore, we also focused on high-normal albuminuria from 15 to $30 \mathrm{mg} \mathrm{g}^{-1} \mathrm{Cr}$.

This study was approved by the Ethics committee of Tohoku Rosai Hospital. The purpose of this study was fully explained to all participants, and written consent was obtained from them.

\section{Statistical analysis}

Of the 6675 candidates, 3166 (47.4\%) underwent health checkups. Of these, 136 subjects were excluded because of postprandial blood sampling $(n=97)$, erythrocyturia $(n=25)$ and macroalbuminuria $(n=14)$. Furthermore, 897 subjects being treated with either anti-hypertensive or anti-diabetic medications were excluded. Finally, 2133 untreated subjects were included in the final analysis.
Data are presented as mean \pm s.d. or median (minimum, maximum) according to the data distribution. Student's $t$-test or the Mann-Whitney $U$-test was used for comparisons between groups. The $\chi^{2}$-test was used for comparing categorical variables.

For the primary analyses, we used logistic regression to calculate the odds ratio for microalbuminuria compared with normoalbuminuria while simultaneously adjusting for age, sex and multiple covariates. For secondary analyses, we used logistic regression to assess the odds of a subject being within the highnormal albuminuria range from 15 to $30 \mathrm{mg} \mathrm{g}^{-1} \mathrm{Cr}$ compared with subjects with normoalbuminuria $\left(<15 \mathrm{mgg}^{-1} \mathrm{Cr}\right)$.

In this study, the odds ratios for microalbuminuria in normal blood pressure (120-129/80-84 $\mathrm{mm} \mathrm{Hg}$ ), high-normal blood pressure (130-139/85$89 \mathrm{~mm} \mathrm{Hg}$ ), grade I hypertension (140-159/90-99 $\mathrm{mm} \mathrm{Hg}$ ), or grade II or III hypertension $(\geqslant 160 / 100 \mathrm{~mm} \mathrm{Hg})$ were calculated in reference to the optimal blood pressure $(<120 / 80 \mathrm{~mm} \mathrm{Hg}) .{ }^{18}$ Because very few subjects had grade III hypertension, they were combined with subjects with grade II hypertension. Likewise, the odds ratios of microalbuminuria in the high-normal blood glucose group $\left(100-109 \mathrm{mg} \mathrm{dl}^{-1}\right)$, the impaired fasting glucose group $\left(110-125 \mathrm{mg} \mathrm{dl}^{-1}\right)$ and the diabetes group $\left(\geqslant 126 \mathrm{mg} \mathrm{dl}^{-1}\right)$ were calculated in reference to a fasting blood glucose level of $<100 \mathrm{mg} \mathrm{dl}^{-1}$. JMP (version 5.0 for Windows; SAS Institute, Cary, NC, USA) was used for statistical analysis. Statistical significance was determined at $P<0.05$.

\section{RESULTS}

Of 2133 subjects under no anti-hypertensive or anti-diabetic medication, $118(5.5 \%)$ had microalbuminuria. Table 1 shows the clinical background of the normoalbuminuria and microalbuminuria groups. Compared with the normoalbuminuria group, the microalbuminuria group included older participants, more men and exhibited higher prevalence of metabolic syndrome. The blood pressure, triglyceride and blood glucose levels in the microalbuminuria group were higher, whereas their high-density lipoprotein level was lower. Serum uric acid concentration was higher in the microalbuminuria group, but there was no difference in terms of renal function between the groups.

Of the 2015 normoalbuminuric subjects, 162 (8.0\%) showed highnormal albuminuria with $15-30 \mathrm{mgg}^{-1} \mathrm{Cr}$. Table 2 compares the clinical characteristics of subjects having high-normal albuminuria and those of subjects having normoalbuminuria with $<15 \mathrm{mg} \mathrm{g}^{-1} \mathrm{Cr}$. Compared with the normoalbuminuria group, the high-normal albuminuria group included older patients and suffered from

\section{Table 1 Clinical characteristics of normoalbuminuria and microalbuminuria groups}

\begin{tabular}{|c|c|c|c|}
\hline Variables & Normoalbuminuria $(\mathrm{n}=2015)$ & Microalbuminuria $(\mathrm{n}=118)$ & $\mathrm{P}$-value \\
\hline Age (years) & $62.0(29.0,84.0)$ & $64.5(31.0,82.0)$ & $<0.005$ \\
\hline Gender (men, \%) & 36.9 & 50 & $<0.01$ \\
\hline Metabolic syndrome (\%) & 14.8 & 33.0 & $<0.0001$ \\
\hline Waist circumference cm) & $84.4 \pm 8.9$ & $87.6 \pm 9.4$ & $<0.0001$ \\
\hline $\mathrm{BMI}\left(\mathrm{kg} \mathrm{m}^{-2}\right)$ & $22.8 \pm 3.1$ & $24.0 \pm 3.5$ & $<0.0005$ \\
\hline Systolic blood pressure (mm Hg) & $124.6 \pm 18.1$ & $137.1 \pm 21.4$ & $<0.0001$ \\
\hline Diastolic blood pressure (mm Hg) & $71.9 \pm 11.2$ & $79.7 \pm 13.1$ & $<0.0001$ \\
\hline $\mathrm{LDL}\left(\mathrm{mg} \mathrm{dl} \mathrm{l}^{-1}\right)$ & $124.9 \pm 33.0$ & $124.8 \pm 30.7$ & NS \\
\hline $\mathrm{HDL}\left(\mathrm{mg} \mathrm{dl}^{-1}\right)$ & $65.7 \pm 16.5$ & $61.0 \pm 17.2$ & $<0.005$ \\
\hline Triglyceride (mg dl $\left.{ }^{-1}\right)$ & $87.0(22.0,784.0)$ & $112.5(28.0,723.0)$ & $<0.0001$ \\
\hline Fasting blood glucose $\mathrm{mg} \mathrm{dl}^{-1}$ ) & $88.0(56.0,354)$ & $90.5(72.0,197.0)$ & $<0.0005$ \\
\hline HbAlc (\%) & $5.4(4.0,13.5)$ & $5.5(4.3,11.6)$ & $<0.0005$ \\
\hline $\operatorname{Cr}\left(\mathrm{mg} \mathrm{dl}^{-1}\right)$ & $0.68 \pm 0.14$ & $0.70 \pm 0.16$ & NS \\
\hline Uric acid (mg dl $\left.{ }^{-1}\right)$ & $4.8 \pm 1.2$ & $5.2 \pm 1.2$ & $<0.0001$ \\
\hline Dyslipidemia treatment (\%) & 10.0 & 6.8 & NS \\
\hline Current smoker (\%) & 17.3 & 29.7 & $<0.005$ \\
\hline Estimated GFR ( $\mathrm{ml} \mathrm{min}{ }^{-1}$ per $\left.1.73 \mathrm{~m}^{2}\right)$ & $79.1 \pm 14.9$ & $79.9 \pm 16.8$ & NS \\
\hline
\end{tabular}

Abbreviations: BMI, body mass index; Cr, creatinine; GFR, glomerular filtration rate; HbAlc, hemoglobin Alc; HDL, high-density lipoprotein; LDL, low-density lipoprotein; NS, not significant. 
Table 2 Clinical characteristics of normoalbuminuria group with urinary albumin excretion less than $15 \mathrm{mgg}^{-1} \mathrm{Cr}_{\text {and }} \mathrm{high}$ normal albuminuria group

\begin{tabular}{|c|c|c|c|}
\hline Variables & Normoalbuminuria $(\mathrm{n}=1853)$ & High-normal albuminuria $(\mathrm{n}=162)$ & P-value \\
\hline Age (years) & $61.0(29.0,84.0)$ & $64.0(29.0,82.0)$ & $<0.0001$ \\
\hline Gender (men, \%) & 37.0 & 35.2 & NS \\
\hline Metabolic syndrome (\%) & 13.6 & 28.4 & $<0.0001$ \\
\hline Waist circumference $(\mathrm{cm})$ & $84.2 \pm 8.8$ & $87.2 \pm 9.4$ & $<0.0001$ \\
\hline $\mathrm{BMI}\left(\mathrm{kg} \mathrm{m}^{-2}\right)$ & $22.7 \pm 3.1$ & $23.7 \pm 3.6$ & $<0.0005$ \\
\hline Systolic blood pressure (mm Hg) & $123.8 \pm 17.6$ & $134.5 \pm 19.9$ & $<0.0001$ \\
\hline Diastolic blood pressure (mm Hg) & $71.5 \pm 10.9$ & $77.0 \pm 12.6$ & $<0.0001$ \\
\hline LDL (mg dl $\left.{ }^{-1}\right)$ & $124.5 \pm 32.4$ & $128.7 \pm 39.6$ & NS \\
\hline $\mathrm{HDL}\left(\mathrm{mg} \mathrm{dl}^{-1}\right)$ & $65.9 \pm 16.6$ & $64.1 \pm 16.2$ & NS \\
\hline Triglyceride (mg dl-1) & $87.0(22.0,784.0)$ & $94.5(39.0,541.0)$ & $<0.01$ \\
\hline Fasting blood glucose $\left(\mathrm{mg} \mathrm{dl}^{-1}\right)$ & $88.0(56.0,307.0)$ & $90.0(66.0,354.0)$ & $<0.0001$ \\
\hline HbAlc (\%) & $5.4(4.0,12.4)$ & $5.7(4.5,13.5)$ & $<0.0005$ \\
\hline $\mathrm{Cr}\left(\mathrm{mg} \mathrm{dl}{ }^{-1}\right)$ & $0.68 \pm 0.14$ & $0.68 \pm 0.16$ & NS \\
\hline Uric acid (mg dl $\left.{ }^{-1}\right)$ & $4.7 \pm 1.2$ & $4.8 \pm 1.2$ & NS \\
\hline Dyslipidemia treatment (\%) & 9.8 & 12.3 & NS \\
\hline Current smoker (\%) & 17.4 & 16.0 & NS \\
\hline Estimated GFR ( $\mathrm{ml} \mathrm{min}-1$ per $\left.1.73 \mathrm{~m}^{2}\right)$ & $79.2 \pm 14.7$ & $77.9 \pm 16.7$ & NS \\
\hline
\end{tabular}

Abbreviations: BMI, body mass index; Cr, creatinine; GFR, glomerular filtration rate; HbAlc, hemoglobin Alc; HDL, high-density lipoprotein; LDL, low-density lipoprotein; NS, not significant.

metabolic syndrome more commonly. In addition, their blood pressure, triglyceride levels and blood glucose concentration were higher.

Figure 1 shows the prevalence of microalbuminuria and highnormal albuminuria in each blood pressure and blood glucose category. The prevalence of high-normal albuminuria was higher than microalbuminuria at all reference categories $(4.2 \%$ vs. $2.5 \%$ for systolic blood pressure, $6.6 \%$ vs. $3.7 \%$ for diastolic blood pressure and $7.1 \%$ vs. $4.5 \%$ for fasting blood sugar). The prevalence of both microalbuminuria and high-normal albuminuria increased with increase in each of systolic blood pressure, diastolic blood pressure and fasting blood glucose. The prevalence of high-normal albuminuria was higher than that of microalbuminuria in all blood pressure and blood glucose categories, except the high-normal diastolic blood pressure and impaired fasting glucose categories.

Table 3 shows the odds ratio of having microalbuminuria according to each level of systolic blood pressure, diastolic blood pressure and fasting glucose compared with their respective references. The left column shows the data adjusted for age and sex; the right column shows the data adjusted for all covariates. These results show that the odds ratio of having microalbuminuria in subjects with high-normal systolic blood pressure is significantly greater than in subjects with optimal systolic blood pressure. The odds ratio adjusted for all covariates increased with an increase in the systolic blood pressure. Regarding diastolic blood pressure, the odds ratio of having microalbuminuria started increasing at the high-normal level but did not exhibit a linear relationship as observed in the case with systolic blood pressure. The odds ratio tended to increase at the high-normal glucose levels compared with normal levels, although the change was not statistically significant. However, the odds ratio markedly increased from the impaired fasting glucose level, increasing further at the level of diabetes.

Table 4 shows the odds ratio of having high-normal albuminuria for each level of systolic and diastolic blood pressure, and blood glucose compared with each reference category. High-normal systolic blood pressure was significantly associated with increased odds of high-normal albuminuria. The odds ratio significantly and linearly increased with increasing systolic blood pressure. Regarding diastolic blood pressure, the odds ratio remained unchanged until the high-normal category but significantly elevated from grade I hypertension category onward. The multivariate odds ratio for having high-normal albuminuria did not increase significantly until the level of impaired fasting glucose and increased significantly at the level of diabetes.

\section{DISCUSSION}

This is the first study that examines the thresholds of blood pressure and blood glucose at which the odds ratio of having microalbuminuria begins to increase in the general Asian population. We found that the odds ratio for microalbuminuria increases significantly from the stage of high-normal blood pressure and impaired fasting glucose level compared with their reference categories. These data provide very important suggestions about the stage at which intervention should be initiated.

Regarding the relationship between high-normal blood pressure and microalbuminuria, the results from previous studies are not entirely consistent; some report a significant relationship, ${ }^{10,12}$ whereas no significant relationships were reported in populations from the Seychelles ${ }^{11}$ or Nord-Trndelag. ${ }^{13}$ Although the reason behind this discrepancy is unclear, older people may be easily affected by increases in blood pressure. ${ }^{10,12}$ In fact, the mean age of our population, 60 years, is much higher than the mean ages of the Seychelles (range, 25-64 years) and Nord-Trndelag (mean age, 49 years) populations. Ethnicities such as negroids or Asians are reported to have a higher risk of albuminuria than Caucasians. ${ }^{10}$ However, the prevalence of microalbuminuria in this study was $5.5 \%$, which is somewhat lower than the $6-10 \%$ prevalence reported in the general Caucasian population. ${ }^{8,10,19}$ Therefore, the risk of microalbuminuria is not necessarily high in the population surveyed in this study. These results suggest that glomerular damage starts at high-normal blood pressure, regardless of other risks. Our data support the notions that the risk of systemic endothelial damage is minimal at optimal blood pressure and that the risk of subsequently developing cardiovascular or renal disease increases in parallel with elevations in blood pressure. ${ }^{20-22}$ 

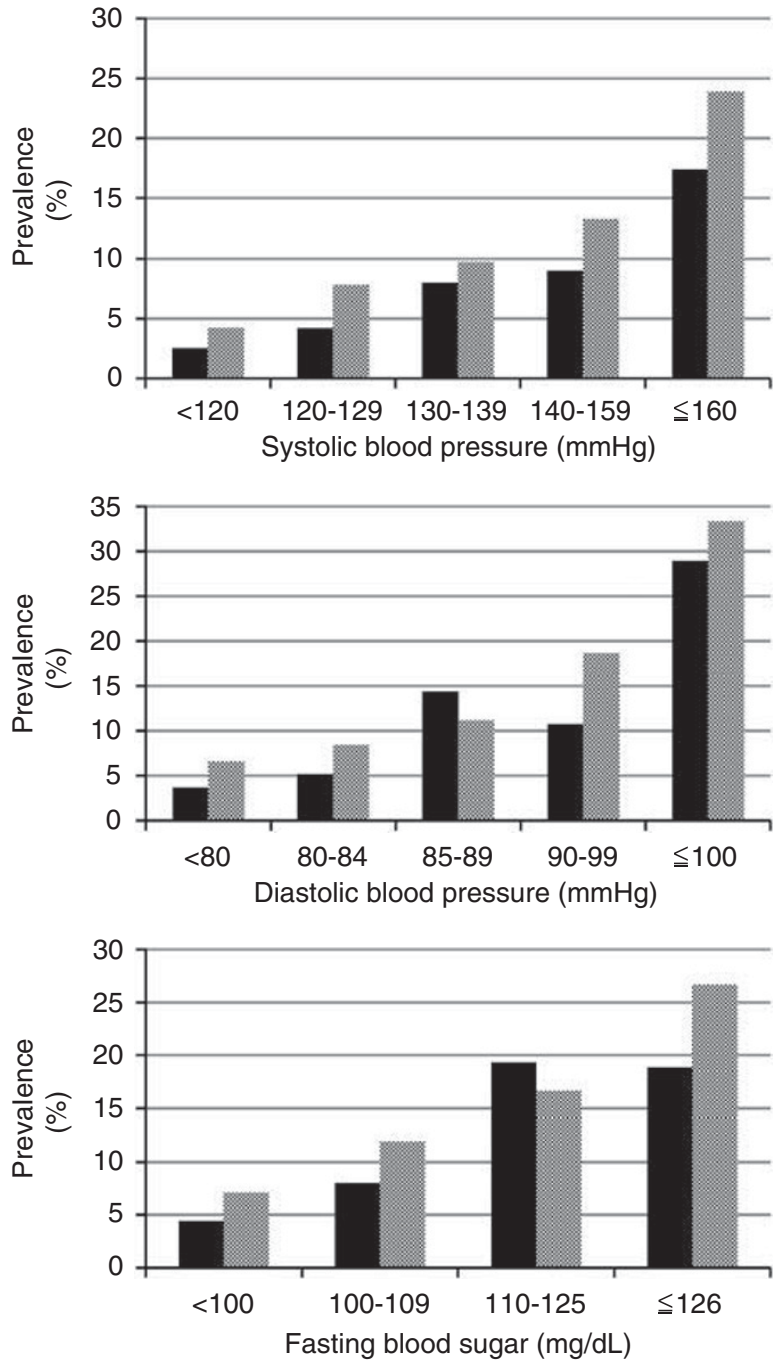

Figure 1 Prevalence of microalbuminuria and high-normal albuminuria in each blood pressure and blood glucose category. Closed and dotted bars indicate microalbuminuria and high-normal albuminuria data, respectively.

The relationship between diastolic blood pressure level and the odds ratio of having microalbuminuria was not so clearly linear as observed on systolic blood pressure. This suggests that the effects of systolic and diastolic blood pressure have different effects on glomerular damage. Our data show that systolic blood pressure has a higher predictive accuracy for the risk of glomerular endothelial damage than diastolic blood pressure. This finding is consistent with a previous report showing that systolic blood pressure predominantly affects cardiovascular events rather than diastolic blood pressure in elderly people. ${ }^{23}$ In fact, $67 \%$ of our subjects were 60 years or older. Therefore, we may need to perform another study to determine whether the results of the present study are applicable to younger people.

With respect to the relationship between fasting blood glucose levels and the odds ratio for microalbuminuria, the multivariate-adjusted odds ratio increased significantly from the impaired fasting glucose level compared with normal glucose level. Our data are consistent with previous reports in the general population ${ }^{24}$ or hypertensive patients. ${ }^{25}$ Thus, interventions for patients with high-normal blood pressure and impaired fasting glucose could reduce cardiovascular and renal risks in the general population.
Table 3 Age and sex-adjusted, and fully adjusted odds ratio for the presence of microalbuminuria

\begin{tabular}{|c|c|c|}
\hline & Age and sex adjusted & Fully adjusted \\
\hline \multicolumn{3}{|c|}{ Systolic blood pressure } \\
\hline$<120$ & 1.00 & 1.00 \\
\hline $120-129$ & $1.598(0.835,3.021)$ & $1.425(0.738,2.714)$ \\
\hline $130-139$ & $3.053(1.749,5.435)$ & $2.568(1.450,4.627)$ \\
\hline $140-159$ & $3.502(1.950,6.377)$ & $2.859(1.563,5.293)$ \\
\hline $160 \leqq$ & $7.381(3.538,15.093)$ & $5.687(2.673,11.850)$ \\
\hline \multicolumn{3}{|c|}{ Diastolic blood pressure } \\
\hline$<80$ & 1.00 & 1.00 \\
\hline $80-84$ & $1.221(0.627,2.211)$ & $1.020(0.513,1.884)$ \\
\hline $85-89$ & $3.824(2.256,6.312)$ & $3.393(1.962,5.715)$ \\
\hline 90-109 & $2.597(1.242,5.002)$ & $2.332(1.098,4.571)$ \\
\hline $100 \leqq$ & $9.415(4.271,19.567)$ & $7.834(3.499,16.561)$ \\
\hline \multicolumn{3}{|c|}{ Fasting blood sugar } \\
\hline$<100$ & 1.00 & 1.00 \\
\hline 100-109 & $1.621(0.859,2.854)$ & $1.554(0.758,3.120)$ \\
\hline $110-125$ & $4.277(2.141,8.020)$ & $4.557(1.874,11.738)$ \\
\hline $126 \leqq$ & $4.433(1.739,9.915)$ & $8.083(1.565,45.960)$ \\
\hline
\end{tabular}

Fully-adjusted model for systolic and diastolic blood pressure, age, sex, body mass index, triglyceride, fasting blood sugar, uric acid and smoking status were included. Statistically significant values are indicated in boldface.

Table 4 Age and sex-adjusted, and fully adjusted odds ratio for the presence of high-normal albuminuria

\begin{tabular}{|c|c|c|}
\hline & Age and sex adjusted & Fully adjusted \\
\hline \multicolumn{3}{|c|}{ Systolic blood pressure } \\
\hline$<120$ & 1.00 & 1.00 \\
\hline $120-129$ & $1.776(1.077,2.917)$ & $1.618(0.972,2.680)$ \\
\hline $130-139$ & $2.102(1.294,3.423)$ & $1.736(1.053,2.863)$ \\
\hline $140-159$ & $2.860(1.750,4.688)$ & $2.332(1.406,3.874)$ \\
\hline $160 \leqq$ & $5.831(2.987,11.076)$ & $4.930(2.497,9.467)$ \\
\hline \multicolumn{3}{|c|}{ Diastolic blood pressure } \\
\hline$<80$ & 1.00 & 1.00 \\
\hline $80-84$ & $1.181(0.692,1.926)$ & $1.091(0.636,1.788)$ \\
\hline $85-89$ & $1.660(0.913,2.846)$ & $1.418(0.763,2.473)$ \\
\hline 90-109 & $3.014(1.645,5.270)$ & $2.671(1.432,4.748)$ \\
\hline $100 \leqq$ & $6.375(2.646,14.369)$ & $5.600(2.319,12.666)$ \\
\hline \multicolumn{3}{|c|}{ Fasting blood glucose } \\
\hline$<100$ & 1.00 & 1.00 \\
\hline 100-109 & $1.684(0.973,2.775)$ & $1.385(0.792,2.307)$ \\
\hline $110-125$ & $2.563(1.138,5.204)$ & $2.029(0.885,4.201)$ \\
\hline $126 \leqq$ & $4.760(1.937,10.637)$ & $3.394(1.343,7.821)$ \\
\hline
\end{tabular}

Fully adjusted model for systolic and diastolic blood pressure, age, sex, body mass index, triglyceride, fasting blood sugar were included. Statistically significant values are indicated in boldface.

High-normal albuminuria, which is defined as a urinary albumin concentration of $15-30 \mathrm{mgg}^{-1} \mathrm{Cr}$, was present in 162 of 2015 normoalbuminuric subjects $(8 \%)$.

The prevalence of high-normal albuminuria was higher than that of microalbuminuria at almost all blood pressure and fasting blood glucose categories, except the high-normal diastolic blood pressure and impaired fasting glucose categories. The multivariate-adjusted 
odds ratio for the presence of high-normal albuminuria increased above high-normal systolic blood pressure. Regarding diastolic blood pressure, the odds ratio increased significantly above the grade I hypertension category. Thus, high-normal albuminuria is more sensitive to changes in systolic blood pressure than changes in diastolic blood pressure.

In contrast to microalbuminuria, impaired fasting glucose was not associated with significantly increased odds for high-normal albuminuria. This indicates that microalbuminuria is more sensitive to changes in the fasting blood glucose levels than high-normal albuminuria. Our data suggest that lowering the cutoff value of urinary albumin excretion does not necessarily enhance the detection of glomerular endothelial damage due to hyperglycemia.

This study had few limitations. First, the surveyed individuals were recipients of medical care benefits from the town and therefore were farmers, fishermen, self-employed or retirees; in other words, salaried employees were not included. Therefore, there is a bias in terms of the occupations of the participants. Second, the participant rate for health checkups was $47 \%$. Thus, the present data may not accurately reflect the characteristics of the general population. In fact, the frequency of microalbuminuria in this study $(5.5 \%)$ was much lower than that of the other Japanese general populations such as those of Iwate Kenpoku $(19 \%)^{26}$ and Takahata (14\%). ${ }^{27}$ People who participate in regular health checkups are normally healthier and have better prognosis than people who do not. ${ }^{28}$ Third, microalbuminuria was determined only once by using random spot urine samples. Because of variations in the excretion rate of urinary albumin, multiple measurements should preferably be performed for the diagnosis of microalbuminuria. However, conducting multiple measurements during health checkups is unrealistic. In the PREVEND study, measuring the albumin/creatinine ratio from the first morning, void urine samples proved to be a good alternative to measuring 24-h urinary albumin excretion in order to predict cardiovascular morbidity and all-cause mortality. ${ }^{29}$ Finally, because this is a cross-sectional study, the cause-effect relationship between albuminuria and blood pressure or blood glucose could not be clarified. To clarify this issue, a further longitudinal observation study is required.

In conclusion, we examined the thresholds of blood pressure and blood glucose at which the odds ratio of having microalbuminuria begins to increase. The results show that the odds ratio for microalbuminuria increases significantly above high-normal blood pressure levels in reference to the optimal blood pressure. In addition, the odds ratio for microalbuminuria starts increasing with impaired fasting glucose.

\section{ACKNOWLEDGEMENTS}

This study was supported by Grants-in-Aid from the Japan Labour, Health and Welfare Organization.

1 Kohro T, Furui Y, Mitsutake N, Fujii R, Morita H, Oku S, Ohe K, Nagai R. The Japanese national health screening and intervention program aimed at preventing worsening of the metabolic syndrome. Int Heart J 2008; 49: 193-203.

2 Deckert T, Kofoed-Enevoldsen A, Nørgaard K, Borch-Johnsen K, Feldt-Rasmussen B, Jensen T. Microalbuminuria. Implications for micro- and macrovascular disease. Diabetes Care 1992; 15: 1181-1191.

3 Pedrinelli R, Penno G, Dell'Omo G, Bandinelli S, Giorgi D, Di Bello V, Navalesi R, Mariani M. Microalbuminuria and transcapillary albumin leakage in essential hypertension. Hypertension 1999; 34: 491-495.

4 Mogensen CE. Microalbuminuria predicts clinical proteinuria and early mortality in maturity-onset diabetes. N Engl J Med 1984; 310: 356-360.
5 Bigazzi R, Bianchi S, Baldari D, Campese VM. Microalbuminuria predicts cardiovascular events and renal insufficiency in patients with essential hypertension. J Hypertens 1998; 16: 1325-1333.

6 Klausen K, Borch-Johnsen K, Feldt-Rasmussen B, Jensen G, Clausen P, Scharling H, Appleyard M, Jensen JS. Very low levels of microalbuminuria are associated with increased risk of coronary heart disease and death independently of renal function, hypertension, and diabetes. Circulation 2004; 110: 32-35.

7 Gerstein HC, Mann JF, Yi Q, Zinman B, Dinneen SF, Hoogwerf B, Hallé JP, Young J, Rashkow A, Joyce C, Nawaz S, Yusuf S, HOPE Study Investigators. Albuminuria and risk of cardiovascular events, death, and heart failure in diabetic and nondiabetic individuals. JAMA 2001; 286: 421-426.

8 Hillege HL, Fidler V, Diercks GF, van Gilst WH, de Zeeuw D, van Veldhuisen DJ, Gans RO, Janssen WM, Grobbee DE, de Jong PE, Prevention of Renal and Vascular End Stage Disease (PREVEND) Study Group. Urinary albumin excretion predicts cardiovascular and noncardiovascular mortality in general population. Circulation 2002; 106: 1777-1782.

9 Arnlöv J, Evans JC, Meigs JB, Wang TJ, Fox CS, Levy D, Benjamin EJ, D'Agostino RB, Vasan RS. Low-grade albuminuria and incidence of cardiovascular disease events in nonhypertensive and nondiabetic individuals: the Framingham Heart Study. Circulation 2005; 112: 969-975.

10 Knight EL, Kramer HM, Curhan GC. High-normal blood pressure and microalbuminuria. Am J Kidney Dis 2003; 41: 588-595.

11 Pruijm MT, Madeleine G, Riesen WF, Burnier M, Bovet P. Prevalence of microalbuminuria in the general population of Seychelles and strong association with diabetes and hypertension independent of renal markers. J Hypertens 2008; 26: 871-877.

12 Jiang X, Srinivasan SR, Radhakrishnamurthy B, Dalferes Jr ER, Bao W, Berenson GS. Microalbuminuria in young adults related to blood pressure in a biracial (black-white) population. The Bogalusa Heart Study. Am J Hypertens 1994; 7: 794-800.

13 Romundstad S, Holmen J, Hallan H, Kvenild K, Krüger O, Midthjell K. Microalbuminuria, cardiovascular disease and risk factors in a nondiabetic/nonhypertensive population. The Nord-Trøndelag Health Study (HUNT, 1995-97), Norway. J Intern Med 2002; 252: 164-172.

14 Matsuo S, Imai E, Horio M, Yasuda Y, Tomita K, Nitta K, Yamagata K, Tomino Y, Yokoyama $\mathrm{H}$, Hishida A. Collaborators developing the Japanese equation for estimated GFR. Revised equations for estimated GFR from serum creatinine in Japan. Am J Kidney Dis 2009; 53: 982-992.

15 The Examination Committee of the Criteria for Metabolic Syndrome in Japan. Definition and criteria of the metabolic syndrome in Japan. J Jpn Society Intern Med 2005; 94: 188-201, (in Japanese).

$16 \mathrm{~K} / \mathrm{DOQ}$ clinical practice guidelines on hypertension and antihypertensive agents in chronic kidney disease. Kidney disease outcomes quality initiative (K/DOQI). Am J Kidney Dis 2004; 43(5 Suppl 1): S1-S290.

17 Wachtell $\mathrm{K}$, Ibsen $\mathrm{H}$, Olsen MH, Borch-Johnsen K, Lindholm LH, Mogensen CE, Dahlöf B, Devereux RB, Beevers G, de Faire U, Fyhrquist F, Julius S, Kjeldsen SE, Kristianson K, Lederballe-Pedersen O, Nieminen MS, Okin PM, Omvik P, Oparil S, Wedel $\mathrm{H}$, Snapinn SM, Aurup P. Albuminuria and cardiovascular risk in hypertensive patients with left ventricular hypertrophy: the LIFE study. Ann Intern Med 2003; 139: 901-906.

18 Ogihara T, Kikuchi K, Matsuoka H, Fujita T, Higaki J, Horiuchi M, Imai Y, Imaizumi T, Ito S, Iwao H, Kario K, Kawano Y, Kim-Mitsuyama S, Kimura G, Matsubara H, Matsuura H, Naruse M, Saito I, Shimada K, Shimamoto K, Suzuki H, Takishita S, Tanahashi N, Tsuchihashi T, Uchiyama M, Ueda S, Ueshima H, Umemura S, Ishimitsu T, Rakugi H. The Japanese Society of Hypertension Guidelines for the Management of Hypertension (JSH 2009). Hypertens Res 2009; 32: 3-107.

19 Karalliedde J, Viberti G. Microalbuminuria and cardiovascular risk. Am J Hypertens 2004; 17: 986-993.

20 Chobanian AV, Bakris GL, Black HR, Cushman WC, Green LA, Izzo Jr JL, Jones DW, Materson BJ, Oparil S, Wright Jr JT, Roccella EJ. Joint National Committee on Prevention, Detection, Evaluation, and Treatment of High Blood Pressure. National Heart, Lung, and Blood Institute. National High Blood Pressure Education Program Coordinating Committee. The Seventh Report of the Joint National Committee on Prevention, Detection, Evaluation, and Treatment of High Blood Pressure. Hypertension 2003; 42: 1206-1242.

21 Ikeda A, Iso H, Yamagishi K, Inoue M, Tsugane S. Blood pressure and the risk of stroke, cardiovascular disease, and all-cause mortality among Japanese: the JPHC Study. Am J Hypertens 2009; 22: 273-280.

22 Tozawa M, Iseki K, Iseki C, Kinjo K, Ikemiya Y, Takishita S. Blood pressure predicts risk of developing end-stage renal disease in men and women. Hypertension 2003; 41: $1341-1345$

23 Staessen JA, Gasowski J, Wang JG, Thijs L, Den Hond E, Boissel JP, Coope J, Ekbom T, Gueyffier F, Liu L, Kerlikowske K, Pocock S, Fagard RH. Risks of untreated and treated isolated systolic hypertension in the elderly: meta-analysis of outcome trials. Lancet 2000; 355: 865-872.

24 Tapp RJ, Shaw JE, Zimmet PZ, Balkau B, Chadban SJ, Tonkin AM, Welborn TA, Atkins RC. Albuminuria is evident in the early stages of diabetes onset: results from the Australian Diabetes, Obesity, and Lifestyle Study (AusDiab). Am J Kidney Dis 2004; 44: 792-798.

25 Marín R, Rodríguez P, Tranche S, Redón J, Morales-Olivas F, Galgo A, Brito MA, Mediavilla J, Lozano JV, Filozof C. Prevalence of abnormal urinary albumin excretion rate in hypertensive patients with impaired fasting glucose and its association with cardiovascular disease. J Am Soc Nephrol 2006; 17(12 Suppl 3): S178-S188.

26 Nakamura M, Onoda T, Itai K, Ohsawa M, Satou K, Sakai T, Segawa T, Sasaki J, Tonari Y, Hiramori K, Okayama A. Association between serum C-reactive protein levels and microalbuminuria: a population-based cross-sectional study in northern Iwate, Japan. Intern Med 2004; 43: 919-925. 
27 Konta T, Hao Z, Abiko H, Ishikawa M, Takahashi T, Ikeda A, Ichikawa K, Takasaki S, Kubota I. Prevalence and risk factor analysis of microalbuminuria in Japanese general population: the Takahata study. Kidney Int 2006; 70 . 751-756.

28 Hozawa A, Kuriyama S, Watanabe I, Kakizaki M, Ohmori-Matsuda K, Sone T, Nagai M, Sugawara Y, Nitta A, Li Q, Ohkubo T, Murakami Y, Tsuji I. Participation in health check-ups and mortality using propensity score matched cohort analyses. Prev Med 2010; 51: 397-402.

29 Lambers Heerspink HJ, Brantsma AH, de Zeeuw D, Bakker SJ, de Jong PE, Gansevoort RT. Albuminuria assessed from first-morning-void urine samples versus 24-h urine collections as a predictor of cardiovascular morbidity and mortality. Am J Epidemiol 2008; 168: 897-905. 